\title{
Gamma-aminobutyric acid and glutamic acid levels in the auditory pathway of rats with chronic tinnitus: a direct determination using high resolution point-resolved proton magnetic resonance spectroscopy ( $\left.{ }^{1} \mathrm{H}-\mathrm{MRS}\right)$
}

\author{
Thomas Brozoski $^{1}{ }^{*}$, Boris Odintsov $^{2}$ and Carol Bauer ${ }^{1}$ \\ Division of Otolaryngology, Southern Illinois University School of Medicine, Springfield, IL, USA \\ ${ }^{2}$ Biomedical Imaging Center, Beckman Institute for Advanced Science and Technology, University of Illinois, Urbana Champaign, Urbana, IL, USA
}

\section{Edited by:}

Jos J. Eggermont, University of

Calgary Medicine, USA

\section{Reviewed by:}

Thanos Tzounopoulos, University of

Pittsburgh, USA

Helmy Mulders, University of

Western Australia, Australia

*Correspondence:

Thomas Brozoski, Division of Otolaryngology, Southern Illinois

University School of Medicine, 801 N. Rutledge Street, Rm 3205,

PO Box 19629, Springfield, IL, USA. e-mail: tbrozoski@siumed.edu
Damage to the auditory system following high-level sound exposure reduces afferent input. Homeostatic mechanisms appear to compensate for the loss. Overcompensation may produce the sensation of sound without an objective physical correlate, i.e., tinnitus. Several potential compensatory neural processes have been identified, such as increased spontaneous activity. The cellular mechanisms enabling such compensatory processes may involve down-regulation of inhibitory neurotransmission mediated by $\gamma$-amino butyric acid (GABA), and/or up-regulation of excitatory neurotransmission, mediated by glutamic acid (Glu). Because central processing systems are integrated and well-regulated, compensatory changes in one system may produce reactive changes in others. Some or all may be relevant to tinnitus. To examine the roles of GABA and Glu in tinnitus, high resolution point-resolved proton magnetic resonance spectroscopy $\left({ }^{1} \mathrm{H}\right.$-MRS) was used to quantify their levels in the dorsal cochlear nucleus (DCN), inferior colliculus (IC), medial geniculate body (MGB), and primary auditory cortex (A1) of rats. Chronic tinnitus was produced by a single high-level unilateral exposure to noise, and was measured using a psychophysical procedure sensitive to tinnitus. Decreased GABA levels were evident only in the MGB, with the greatest decrease, relative to unexposed controls, obtained in the contralateral MGB. Small GABA increases may have been present bilaterally in $\mathrm{A} 1$ and in the contralateral DCN. Although Glu levels showed considerable variation, Glu was moderately and bilaterally elevated both in the DCN and in A1. In the MGB Glu was increased ipsilaterally but decreased contralaterally. These bidirectional and region-specific alterations in GABA and Glu may reflect large-scale changes in inhibitory and excitatory equilibrium accompanying chronic tinnitus. The present results also suggest that targeting both neurotransmitter systems may be optimal in developing more effective therapeutics.

Keywords: tinnitus animal model, ${ }^{1} \mathrm{H}-\mathrm{MRS}, \mathrm{GABA}$, glutamate, dorsal cochlear nucleus, inferior colliculus, medial geniculate, primary auditory cortex

\section{INTRODUCTION}

Chronic tinnitus affects a large number of people, with perhaps 3-5 percent of the tinnitus population significantly disturbed by their condition. Exposure to damaging high-level sound is likely the leading cause of tinnitus in young people (Muhr and Rosenhall, 2011) and the second leading cause in older adults (Nondahl et al., 2002). Damage to the peripheral auditory system, in the long-term, reduces afferent input to the central auditory system and appears to stimulate compensatory central changes. The compensation, or perhaps overcompensation, may produce the sensation of sound where none exists, i.e., tinnitus. The neural correlates of tinnitus identified in animal studies are summarized in Table 1. Cellular mechanisms responsible for these changes have been hypothesized to include a down-regulation of inhibitory neurotransmission, such as that mediated by the neurotransmitter $\gamma$-amino butyric acid (GABA) and/or an up-regulation of excitatory neurotransmission, such as that mediated by the excitatory neurotransmitter glutamate (Glu). Can alterations in the concentration of these compounds be directly detected in the brains of animals with objectively confirmed evidence of tinnitus?

Over the past decade animal models have contributed significantly to the neuroscience of tinnitus (Roberts et al., 2010). While diverse, all animal models assume that the sensation of tinnitus results from relatively primitive alterations in central auditory processing. In animals, tinnitus is induced by manipulations, such as high-level sound exposure, that commonly produce tinnitus in humans. The presence of tinnitus can be revealed by appropriately designed psychophysical procedures (Brozoski and Bauer, 2008). In the present experiment, the brains of rats with 
Table 1 | Candidate compensatory mechanisms potentially responsible for compensatory "restoration" of central function following sensory organ damage.

Increased spontaneous neural activity.

Increased synchronous activity across parallel afferents.

Increased regularity of action potentials within individual neurons.

High-frequency discharge clustered into bursts of action potentials.

Over-representation of "lost" frequency bands in tonotopic organization.

psychophysical evidence of sound-induced chronic tinnitus were imaged, and point-resolved proton magnetic resonance spectra ( ${ }^{1} \mathrm{H}$-MRS) were obtained from tissue volumes localized to areas in the auditory pathway that have been identified in one or more studies as potentially involved in mediating tinnitus. Analyzed areas included the dorsal cochlear nucleus (DCN), the inferior colliculus (IC), the medial geniculate body (MGB) or auditory thalamus, and primary auditory cortex (A1).

Recent technical improvements have enabled the acquisition of well-resolved spectra from small tissue volumes. Point-resolved spectroscopy (PRESS) can be used to optimize signal strength from small volumes, while ultra-short echo times can be used to reduce signal multiplets thereby improving peak dispersion and the resolution of complex spectra such as those obtained from brain tissue. Insertion of asymmetric variable power RF pulses into the probe sequence can be used to reduce the otherwise intrusive water peak that obscures signals above 3 ppm (Mlynarik et al., 2008). Separation of spectral lines and extraction of weak signals can be further enhanced by using very high-level magnetic fields and additionally through the use of a tunable pickup coil (Odintsov, 2011).

In the present investigation spectra were obtained from brain volumes of interest (VOI). The brain spectra were calibrated against spectra obtained from glass phantoms, filled with known concentrations of GABA and Glu, and comparable in size to the VOI. GABA and Glu were selected for analysis because they are, respectively, the major inhibitory and excitatory neurotransmitters in the auditory pathway; their concentrations are at detectible levels in small brain volumes, and they have been identified as potentially playing a significant role in tinnitus.

\section{MATERIALS AND METHODS SUBJECTS}

Twenty adult male Long-Evans rats (Harlan, Indianapolis, IN), 90 days old at the start of the experiment, were individually housed and maintained at $25^{\circ} \mathrm{C}$ with a $12 / 12 \mathrm{~h}$ reversed light/dark schedule. Ten months prior to spectroscopy 16 of the animals participated in a study examining the effect of supplementary dietary taurine on tinnitus. The experimental protocol was approved by the Laboratory Animal Care and Use Committee of Southern Illinois University School of Medicine and the University of Illinois at Urbana Champaign.

\section{TINNITUS INDUCTION}

Half of the animals $(n=10)$ were unilaterally exposed once to band limited noise for $1 \mathrm{~h}$. These subjects will be referred to as "exposed." The remaining animals $(n=10)$ were treated identically, but unexposed. They will be referred to as "unexposed." Sound exposure parameters were identical to those reported previously to produce tinnitus in rats (Bauer and Brozoski, 2001; Brozoski et al., 2012). All subjects, exposed and unexposed, were anesthetized to an areflexive state, using either an isoflurane/O2 mixture (Aerrane, Baxter Healthcare Corp., Deerfield, IL, USA), or a ketamine/xylazine mixture $(24.6$ and $3 \mathrm{mg} / \mathrm{kg}$, respectively; ketamine, Ketaset, Fort Dodge Animal Health, Fort Dodge, IA; xylazine, Anased, Lloyd Laboratories, Shenandoah, IA). For the exposed animals, peak level was $116 \mathrm{~dB}$ (SPL) centered at $16 \mathrm{kHz}$, with the noise band falling to ambient level at $8 \mathrm{kHz}$ and $24 \mathrm{kHz}$. The sound was delivered monaurally using a speaker driver (FT17H, Fostex, Tokyo, Japan) in a custom enclosure funneling the sound to a flexible tube that fit snugly into the auditory canal. Sound levels were calibrated using a Brüel and Kjaer (Norcross, GA, USA) Pulse sound measurement system (Pulse 13 software), equipped with a 3560C high-frequency module, and a 4138 pressure-field microphone (Brüel and Kjaer) coupled to the transducer using rubber tubing with the internal dimensions of an adult rat external auditory canal. All sound levels reported in the present experiment are unweighted pressure levels re $20 \mu \mathrm{Pa}$.

\section{HEARING LEVELS}

Hearing thresholds were determined immediately before and after exposure (for exposed rats) using auditory brainstem-evoked potentials (ABR). They were also obtained at the conclusion of tinnitus testing. ABR measurements were obtained using either a TDT System 3 Real Time Signal Processing System running BioSig32 and SigGen (Tucker Davis Technologies, Alachua, FL, USA), or an IHS Smart EP System, running IHS High Frequency Software (v. 2.33) and using IHS high frequency transducers (HFT9911-20-0035, Intelligent Hearing Systems, Miami, FL). Evoked responses were differentially recorded from a subcutaneous vertex needle electrode referenced to an electrode at the occiput. Evoked responses for $10 \mathrm{msec}$ epochs following stimulus onset were amplified $\times 100,000$, bandpass filtered $(100-3000 \mathrm{~Hz})$, and averaged for 512 repetitions of each frequency-intensity level combination. Digitized records of the evoked responses ( $40 \mu \mathrm{sec}$ resolution) were exported to Excel (Microsoft, Redmond, WA, USA) for analysis and threshold determination. Hearing thresholds for each ear were defined by the lowest stimulus level that produced statistically distinct and visually distinct evoked waveforms, defined as the maximum peak-to-peak deflection within the $10 \mathrm{msec}$ window following stimulus onset. Custom applications written for Excel were used for analysis.

\section{TINNITUS ASSESSMENT}

Tinnitus was measured after sound exposure, using a behavioral assay shown to be sensitive to tinnitus in rats, and described in detail elsewhere (Bauer and Brozoski, 2001; Brozoski et al., 2012). Briefly, an operant conditioned-suppression procedure was used to determine the animal's perception of test tones and silent periods embedded in an ambient of low level ( $60 \mathrm{~dB}, \mathrm{SPL})$ broad-band noise (BBN). The key feature of the procedure was 
that animals were required to discriminate between the presence and absence of sound when tested with a variety of sounds varying in composition, frequency, and level. While the features of tinnitus in rats (and humans) cannot be directly known, it is certain that tinnitus cannot sound like silence. The animals were tested daily in commercial operant test chambers (Lafayette Instruments, Mod. 80001, Lafayette, IN, USA) equipped with lid-mounted speakers. Speaker-off periods (i.e., silence) had a special significance because lever pressing for food during the silent periods led to a foot shock at the end of that period. The behavior of interest was lever pressing during randomly presented test sounds ( 1 min duration) that substituted for some of the speaker-off presentations (also $1 \mathrm{~min}$ duration). Assessment sessions consisted of 10 randomly inserted, non-contiguous, presentations. Two of the 10 were always silent (i.e., speaker-off) periods. The remaining eight presentations were of a randomly selected tone or noise, with different levels in each presentation. Lever pressing was quantified using a relative rate measure, the suppression ratio $(R) . R$ was determined as a running measure for successive $1 \mathrm{~min}$ segments of each session using the formula $R=B /(A+B)$, where $A$ was the number of lever presses in the preceding $1 \mathrm{~min}$ segment and $B$ the number of lever presses in the current 1 min segment. $R$ can vary between 0 and 1 . A value of 0 is attained when lever pressing in the current minute is 0 , a value of 0.5 when lever pressing in the current minute is equal to that of the previous minute and a value of 1 when lever pressing in the previous minute is zero. $R$ provided a running index of behavior, in 1 min segments, and enabled a quantitative comparison between subjects as well as unbiased compilation of group data. $R$ is a useful index of perceptual performance in that it is very sensitive to short-term behavioral effects, such as those produced by sensory events, but it is very insensitive to gradual behavioral effects, such as those produced by changes in motivational status, for example, satiation. In the context of the present procedure, it was expected that exposed rats with tinnitus would have lower $R$ values than unexposed rats, when tested with stimuli that resembled their tinnitus. All test sessions were $60 \mathrm{~min}$ in duration. Further details of the psychophysical procedure appear in an open-source document (Brozoski et al., 2012).

Exposed and unexposed rats were treated identically and tested in parallel. Individual animal and group discrimination functions were derived from the final 3-5 sessions of each test series, where performance variability was minimal. Test stimuli were $\mathrm{BBN}$, and $8,10,16,20,24$, and $32 \mathrm{kHz}$ tones. Each stimulus was tested across a range of levels from low to high audibility. Evidence of tinnitus was determined by the divergence of group discrimination functions. For subjects with tinnitus, test stimuli that resembled their tinnitus served as a signal for response (lever press) suppression. In contrast, for unexposed subjects without tinnitus, the signal for suppression was silence. Test stimuli with sensory features resembling tinnitus, therefore, produced greater suppression (i.e., fewer lever presses) in subjects with tinnitus. Previous research (Bauer and Brozoski, 2001) has shown that Long-Evans adult rats, unilaterally exposed to high-level band-limited noise centered at $16 \mathrm{kHz}$, show evidence of tinnitus in a range between 10 and $30 \mathrm{kHz}$.

\section{SPECTROSCOPY: PREPARATION}

Prior to spectroscopy, each animal in its home cage, was placed in a double-wall sound insulated booth for $20 \mathrm{~h}$ without food but with freely available water. The objective was to equate the baseline acoustic environment for all subjects, and to reduce the acoustic ambient to a low-level. The sound floor in this environment across the audible frequency range for rats was less than $10 \mathrm{~dB}$ (SPL). Ten minutes prior to spectroscopy, animals were pretreated i.p. with $10 \mathrm{mg} / \mathrm{kg}$ 3-mercaptopropionic acid (product M5801, Sigma-Aldrich, St. Louis, MO) to arrest post-mortem GABA inflation (van der Heyden and Korf, 1978). Immediately before acquisition, animals were given a lethal dose of anesthetic (Euthasol, Virbac, Ft. Worth, TX), decapitated, the mandible removed, and excess muscle tissue dissected away from the skull. The head was placed in a polyethylene holder along with a $1 \mathrm{~mm}$ diameter glass capillary filled with $\mathrm{CuSO} 4(3 \mathrm{mM})$. The image phantom of the capillary indexed the left hemisphere, making VOI laterality unambiguous.

\section{SPECTROSCOPY: CALIBRATION}

Prior to spectrum acquisition, glass vessels $2 \mathrm{~mm}$ in diameter were prepared with either $10 \mathrm{mM}$ of GABA or $10 \mathrm{mM}$ of Glu dissolved in sterile normal saline. Initial attempts to include one or more calibration vessels along with the brain during spectrographic data acquisition distorted the field, making shimming impossible. Therefore, calibration spectra were obtained either before or after acquisition of brain spectra. Initial calibrations were done with GABA and Glu in combination with compounds, such as creatine, that were expected to produce unwanted spectral lines potentially obscuring those of GABA and Glu. Spectrograms of the mixtures were used to identify GABA and Glu peaks, from among their multiplets, that provided the clearest separation from background. Calibration and peak selection were further refined using arrays of phantoms distributed in the field of view as shown in Figure 1. Taking into account all calibration results, GABA levels were determined using the peak at $2.18 \mathrm{ppm}$ and Glu using the peak at 3.68 ppm (Figure 2).

\section{SPECTROSCOPY: DATA ACQUISITION}

At the conclusion of behavioral testing, the rats were individually imaged and volume-localized ${ }^{1} \mathrm{H}$-MRS spectra were determined. Spectra were obtained using a vertical bore Varian Unity/Inova $600 \mathrm{mHz}$ NMR spectrometer with a $14.1 \mathrm{~T}$ magnet. To reduce the displacement error of microvolume localized ${ }^{1} \mathrm{H}$-MRS, caused by large chemical shifts in the strong magnetic field, a hybrid short-pulse sequence, obtained from R. Gruetter (Mlynarik et al., 2008), was used. The pulse sequence was optimized for signal acquisition in the spectral band containing the neurochemicals of interest, i.e., GABA and Glu. Signals were further optimized using a tunable pickup coil (Odintsov, 2011).

For each animal, an initial MRI brain scan was used to locate the VOI for ${ }^{1} \mathrm{H}-\mathrm{MRS}$. Contiguous transverse (i.e., coronal) slices, $0.5 \mathrm{~mm}$ thick ( $26 \mu \mathrm{m}$ planar resolution), were obtained, extending $13 \mathrm{~mm}$ caudally from Bregma (26 slices total). VOI for ${ }^{1} \mathrm{H}$ MRS were determined within the auditory pathway as indicated in Table 2. The VOI for each auditory region was kept constant and its placement was made as standard as possible using image 


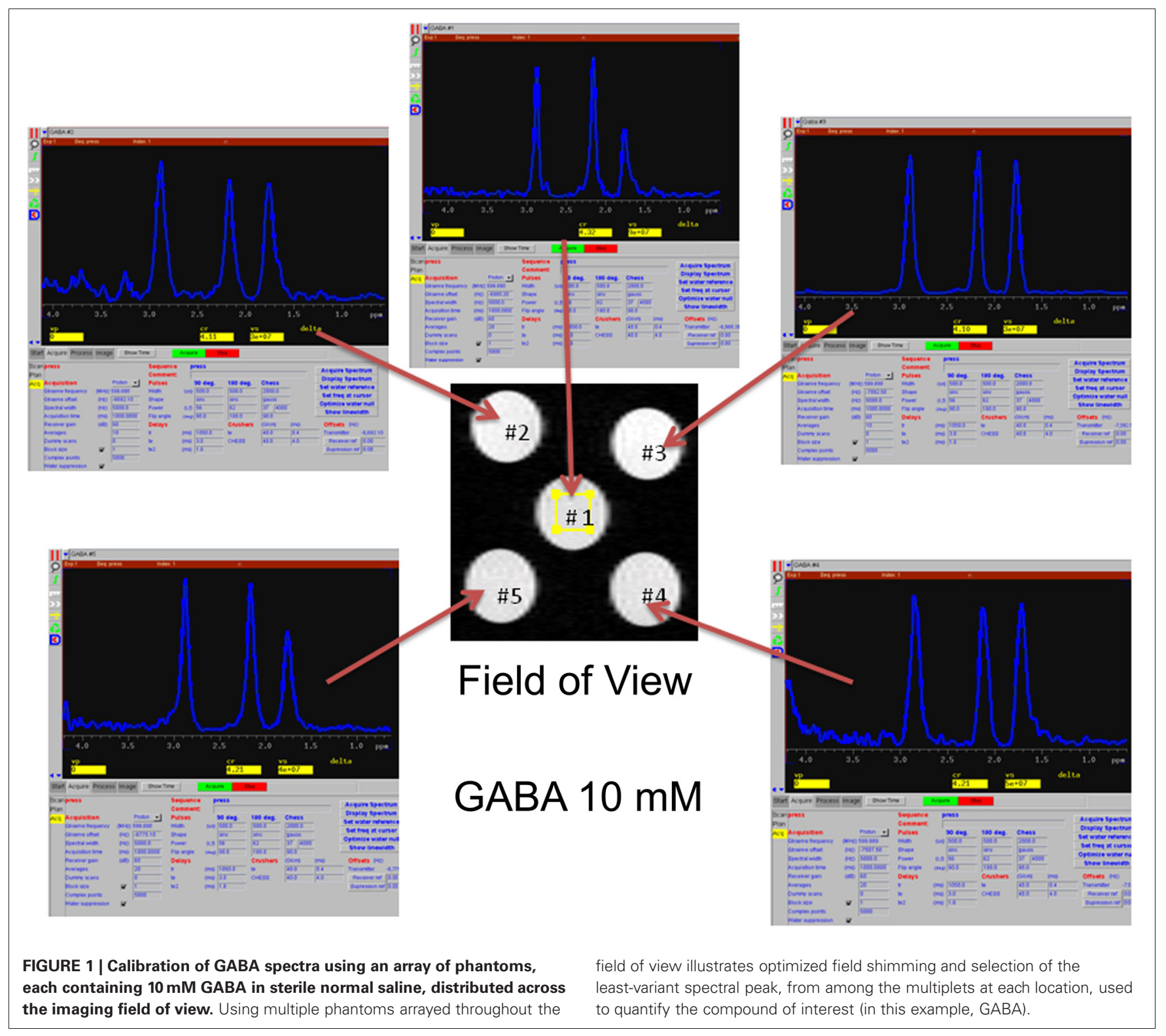

reference points. ${ }^{1} \mathrm{H}$-MRS spectra were obtained bilaterally in the order indicated in Table 2, with acquisition parameters optimized for each VOI. When shimming, the water peak for all spectra was held constant at $4.7 \mathrm{ppm}$, and its line width minimized (typically $30-45 \mathrm{~Hz}$ ). Three hundred scan repetitions were adequate to resolve all spectra, with the exception of the DCN (Table 2).

\section{SPECTROSCOPY: DATA ANALYSIS}

Spectra, as TIFF images, were imported into Image J (ver. 1.44p, http://imagej.nih.gov/ij). Peaks in closest approximation to the calibration peaks for GABA and Glu, were outlined, and the area under each curve (AUC) for each was determined. AUCs were expressed in spectrum baseline (i.e., curve lower bound) units in order to correct for image gain. AUC values were copied to an Excel (2007, Microsoft, Redmond, WA) spreadsheet for analysis. The AUC of each neurochemical was converted to concentration

level (mM), taking into account VOI volume, calibration vessel volume, known calibration concentration, and calibration AUC, as indicated in Equation 1.

$$
\begin{aligned}
\text { VOI est conc }= & {[(\text { VOI AUC } / \text { calib AUC }) \times(\text { calib conc })] } \\
& \times(\text { calib vol } / \text { VOI vol })
\end{aligned}
$$

Pair-wise comparisons were made between exposed and unexposed VOI. Reported significance levels were derived from independent $t$-tests.

\section{RESULTS}

\section{EVIDENCE OF TINNITUS}

Significant tinnitus was evident in the exposed rats approximately four months after exposure. The protocol in the present experiment (exposure before psychophysical training and testing), 


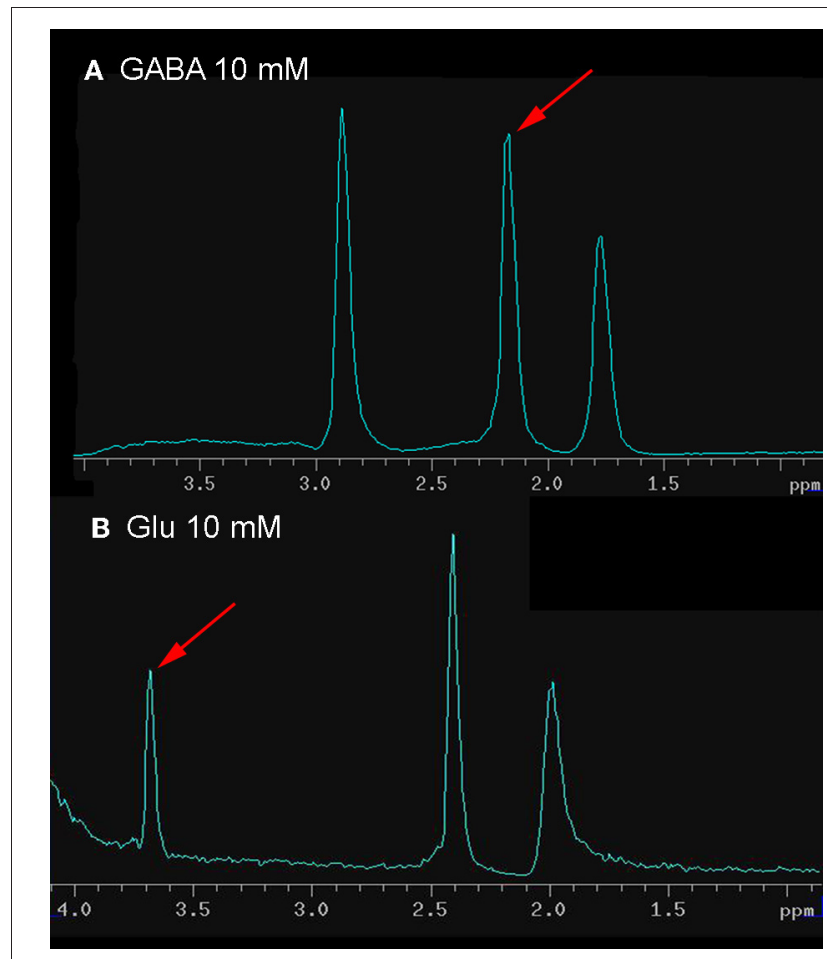

FIGURE 2 | Calibration spectra of GABA and Glu, obtained using the same scanning parameters (see Methods for details) used to capture VOI spectra. The peak, from among the multiplets, used to quantify GABA and Glu is shown by the pointer.

reveals tinnitus as a downshift in discrimination functions. This happens because the sensory correlate of speaker-off periods, i.e., tinnitus in exposed animals, is the conditioned stimulus for response suppression. Therefore, stimuli resembling the speakeroff sensation suppress responding. Frequency-specific suppression was evident in both individual (Figure 3) as well as group data (Figure 4), between 16 and $24 \mathrm{kHz}$. Individual subjects showed some variation in the frequency range of their suppression, from rather narrow (Figure 3A) to broad (Figure 3B). This may reflect the tonality of their tinnitus. In addition, some individuals showed evidence of tinnitus plus hyperacusis.
Nevertheless, all of the exposed rats showed some evidence of tinnitus.

\section{GABA AND GIu LEVELS}

${ }^{1} \mathrm{H}$-MRS data were collected at the conclusion of psychophysical testing. Data from six exposed and five unexposed rats were included in the spectral analysis. Data from seven initial rats were used to adjust and optimize experimental parameters and were not included in the final analysis. Data from two rats were discarded when pituitary tumors were detected. Mean age at the time of spectroscopy was 19.8 and 17.8 months, respectively, for the exposed and unexposed animals. The mean interval between exposure and spectroscopy was 16.2 months. Acquisition of spectra from one animal, along with attendant field shimming, required approximately $7 \mathrm{~h}$ to complete. One session was run per day. Spectra for the four auditory areas of interest, DCN, IC, MGB, and A1, are summarized in Figures 5-8. Each figure depicts selection of the VOI in the top panel, a representative individual spectrum from that VOI in the center panel, and estimated GABA and Glu average levels for exposed and control animals in the bottom panel. GABA and Glu estimated $\mathrm{mM}$ levels are reported separately for each hemisphere, ipsilateral, and contralateral, with respect to sound exposure. Decreased GABA concentration was evident only in the MGB, with the greatest decrease, relative to unexposed controls, obtained in the contralateral MGB (Figure 7; $p=0.033$ ). GABA levels in the exposed MGB were $0.38 \mathrm{mM}$ $( \pm 0.18)$ contralateral and $1.62 \mathrm{mM}( \pm 0.64)$ ipsilateral, as compared to unexposed levels of $2.77 \mathrm{mM}( \pm 1.04)$ contralateral and $2.57 \mathrm{mM}( \pm 1.39)$ ipsilateral. Error $( \pm)$ is the standard error of the mean. Therefore, a GABA decrease, and potential loss of GABAmediated inhibition, was most evident in the auditory thalamus in the direct pathway from the exposed ear, i.e., the contralateral MGB. Small GABA increases may have been present bilaterally in A1 (Figure 8) and in the contralateral DCN (Figure 5) however, these differences were not statistically significant.

Glu level variation, both within and between treatment groups, was higher than GABA variation. Despite the variation, Glu was significantly $(p=0.039)$ elevated in the exposed ipsilateral DCN, $18.77 \mathrm{mM}$ ( \pm 9.76$)$ while unexposed was $12.36 \mathrm{mM}$ $( \pm 2.32)$. Contralateral DCN Glu levels were not significantly different in exposed and unexposed rats. The contralateral

Table $\left.2\right|^{1} \mathrm{H}$-MRS acquisition parameters.

\begin{tabular}{|c|c|c|c|c|c|c|}
\hline \multirow[t]{2}{*}{ Area of interest } & \multirow[t]{2}{*}{ Hemisphere } & \multirow{2}{*}{$\begin{array}{l}\text { Volume }(\mathrm{mm}) \\
\text { of analysis } \\
x, y, z \text { dimension }\end{array}$} & \multirow{2}{*}{$\begin{array}{l}\text { Approximate } \\
\text { on-center caudal } \\
\text { distance from } \\
\text { Bregma }\end{array}$} & \multicolumn{3}{|c|}{ Spectrum acquisition } \\
\hline & & & & $\begin{array}{l}\text { Number of } \\
\text { repetitions }\end{array}$ & $\begin{array}{l}\text { Duration } \\
\text { (min) }\end{array}$ & $\begin{array}{l}\text { Measurement } \\
\text { sequence }\end{array}$ \\
\hline \multirow[t]{2}{*}{ Dorsal cochlear nucleus (DCN) } & Right (ipsilat) & $1.5,2,1.5$ & -10.5 & 2900 & 74 & 5 \\
\hline & Left (contra) & $1.5,2,1.5$ & -10.5 & 2900 & 74 & 8 \\
\hline \multirow[t]{2}{*}{ Inferior colliculus (IC) } & Right (ipsilat) & $2,2,2$ & -7.5 & 300 & 7 & 1 \\
\hline & Left (contra) & $2,2,2$ & -7.5 & 300 & 7 & 2 \\
\hline \multirow[t]{2}{*}{ Medial geniculate body (MGB) } & Right (ipsilat) & $1.5,2,2$ & -5 & 300 & 7 & 6 \\
\hline & Left (contra) & $1.5,2,2$ & -5 & 300 & 7 & 7 \\
\hline \multirow[t]{2}{*}{ Primary auditory cortex (A1) } & Right (ipsilat) & $1.5,2,3$ & -3.5 & 300 & 7 & 3 \\
\hline & Left (contra) & $1.5,2,3$ & -3.5 & 300 & 7 & 4 \\
\hline
\end{tabular}



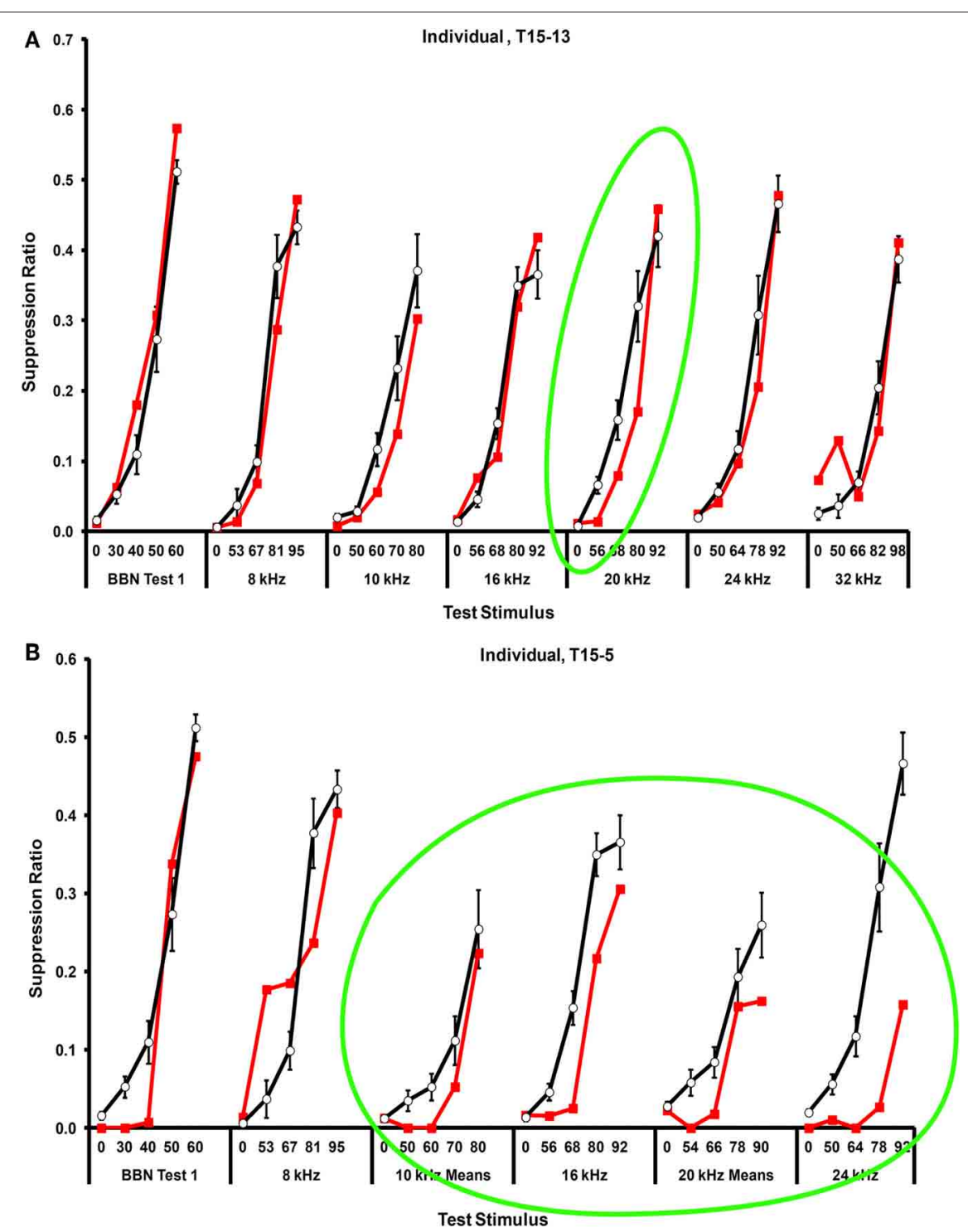

FIGURE 3 | Examples of tinnitus in individual rats. (A) A rat with focal narrow-band tinnitus in the vicinity of $20 \mathrm{kHz}$, and (B) A rat with rather broad-band tinnitus localized between 10 and $24 \mathrm{kHz}$.

Error bars show the standard error of the mean of the unexposed group. Relative rate of lever pressing, as indicated by the suppression ratio (see Text), is shown on the $y$-axis, and test stimulus across stimulus levels $(\mathrm{dB}, \mathrm{SPL})$ is shown on the $x$-axis exposed level was $6.52 \mathrm{mM}( \pm 5.00)$ while unexposed was $3.08 \mathrm{mM}( \pm 2.09)$ (Figure 5). Exposed ipsilateral and contralateral Glu levels were elevated in A1 with respect to unexposed controls, but not significantly so (Figure 8; $p=0.082$, ipsilateral; $p=0.145$, contralateral). However, significance was negatively impacted by high variation in spectra obtained from A1. Field shimming was difficult for A1, and this suggested that the measurement variation may have been a consequence of field anisotropy near the periphery, rather than intrinsic tissue factors. A1 exposed ipsilateral Glu was $3.12 \mathrm{mM}( \pm 1.64)$ while unexposed was $1.32 \mathrm{mM}( \pm 0.54)$. Exposed contralateral A1 Glu was $2.60 \mathrm{mM}$ $( \pm 1.55)$ while unexposed was $0.81 \mathrm{mM}( \pm 0.59)$.

In the MGB Glu was significantly decreased contralaterally (1.24, \pm 0.67 vs. $4.55, \pm 1.13 ; p=0.029)$ and non-signficantly increased ipsilaterally $(4.36, \pm 1.91$ vs. $2.59, \pm 1.11 ; p=0.448)$. In summary, these results suggest enhanced Glu-mediated excitation in the DCN, and potentially in A1, although variation in cortical levels obscured significance. In the IC, exposed vs. unexposed differences in both GABA and Glu were small (Figure 6).

\section{HEARING THRESHOLDS}

The sound exposure used to produce tinnitus was unilateral. This was done to preserve free-field hearing thresholds, a requirement for psychophysical testing. Immediately after exposure (peak sound level at $116 \mathrm{~dB}, \mathrm{SPL}$ ), exposed ear hearing thresholds, as indicated by ABR, were elevated approximately $60 \mathrm{~dB}$ at $20 \mathrm{kHz}$ (Figure 9, top panel). Thresholds for unexposed ears were not affected by the exposure. At the conclusion of psychophysical 

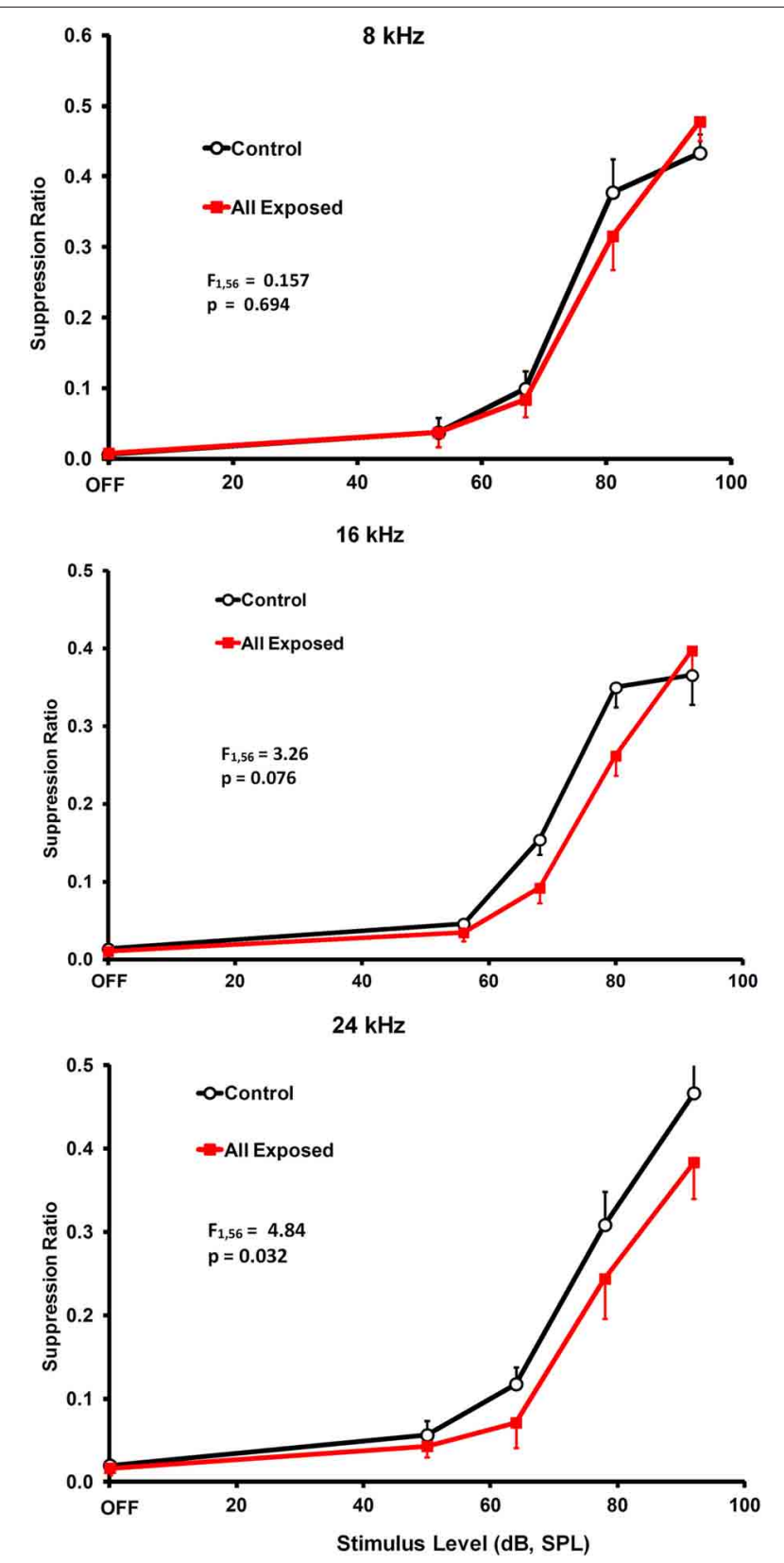

FIGURE 4 | Frequency-specific group evidence of tinnitus. The statistics in each panel represent a comparison of exposed and unexposed groups for stimulus levels above the OFF setting. As in Figure 3, relative lever pressing is shown on the $y$-axis and test stimulus across levels is shown on the $x$-axis. Error bars show the standard error of the mean.

testing, and prior to MRS data collection, ABR thresholds for exposed ears returned to normal levels (Figure 9, bottom panel). Recovery of threshold sensitivity is typical for this level of exposure (Bauer and Brozoski, 2001) in Long Evans rats.

\section{DISCUSSION}

\section{VOLUME LEVEL VS. NEUROTRANSMITTER LEVEL}

The present results indicated that there was a GABA decrease in the MGB and Glu increase in both the DCN and A1,

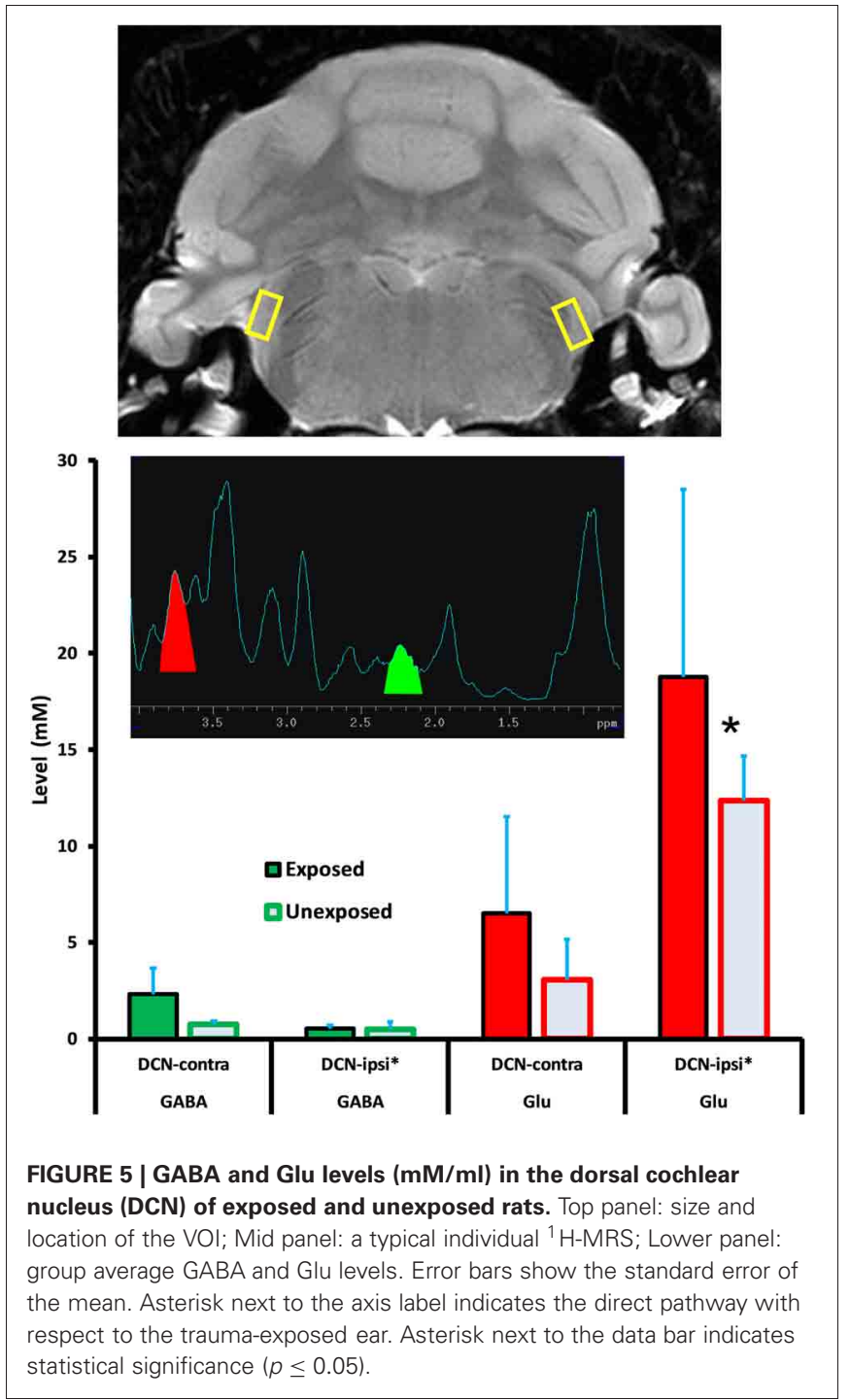

accompanying chronic tinnitus in a rat model. This would support the hypothesis that region-specific loss of inhibition and increased excitatory neurotransmission, underpins chronic acoustically induced tinnitus. However, support of the neurotransmitter hypothesis must be tempered when taking into account limitations of the current method. Neurochemical concentrations were determined ex vivo using point-resolved ${ }^{1} \mathrm{H}$ MRS and a $14.1 \mathrm{~T}$ magnet. Spectra were effectively resolved from volumes down to $4.5 \mathrm{~mm}^{3}$ (i.e., the DCN volume). But the reported levels reflect concentrations of the compounds of interest throughout the tissue volume from which spectra were obtained. Using an MRI scan of each brain, care was taken to place the measurement volume entirely within each area of interest. Within each VOI, however, ${ }^{1} \mathrm{H}-\mathrm{MRS}$ cannot distinguish concentrations in specific sub-VOI compartments, for example, within neurotransmitter vesicles. In addition to their role as neurotransmitters, GABA and Glu also participate in general metabolic functions, for example as components of the tricarboxylic acid cycle GABA shunt. A further complexity is that GABA is derived from Glu by enzymatic decarboxylation. Therefore, the concentration 


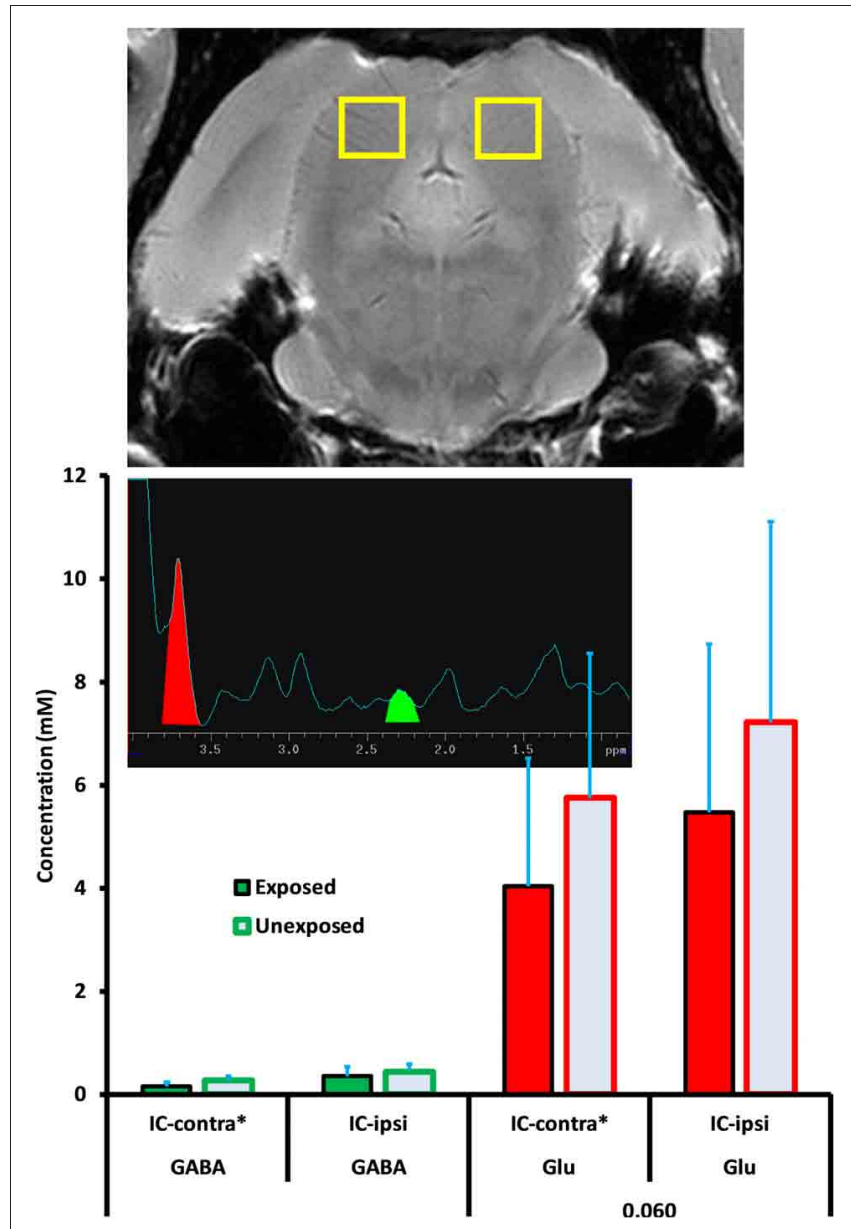

FIGURE 6 | GABA and Glu levels $(\mathrm{mM} / \mathrm{ml}$ ) in the inferior colliculus (IC) of exposed and unexposed rats. No significant differences were obtained between exposed and unexposed animals in the IC. Graphic parameters as in Figure 5.

levels reported in the present research cannot be construed as neurotransmitter levels. However, in the present experiment comparisons were made between exposed and unexposed rats, treated identically except for one high-level sound exposure. On average the sound exposure occurred 16 months prior to spectroscopy. It is unlikely that general metabolic consequences of the exposure would linger to influence the results. A reasonable interpretation would be that between-treatment-group variation in GABA and Glu levels reflects functional changes heavily dependent upon neurotransmitter variation (Stagg et al., 2011b).

\section{REPORTED LEVELS, CALIBRATION, AND COMPARISON TO OTHER ESTIMATES}

The GABA and Glu levels reported in the present study were concentrations determined in reference to external calibration standards (see Methods). In contrast, many ${ }^{1} \mathrm{H}$-MRS studies report relative levels with respect to an internal standard, which is another signal within the spectrum, such as that of N-acetyl aspartate (Stagg et al., 2011a), or water (Puts et al., 2011). When using an internal standard it must be assumed that the standard

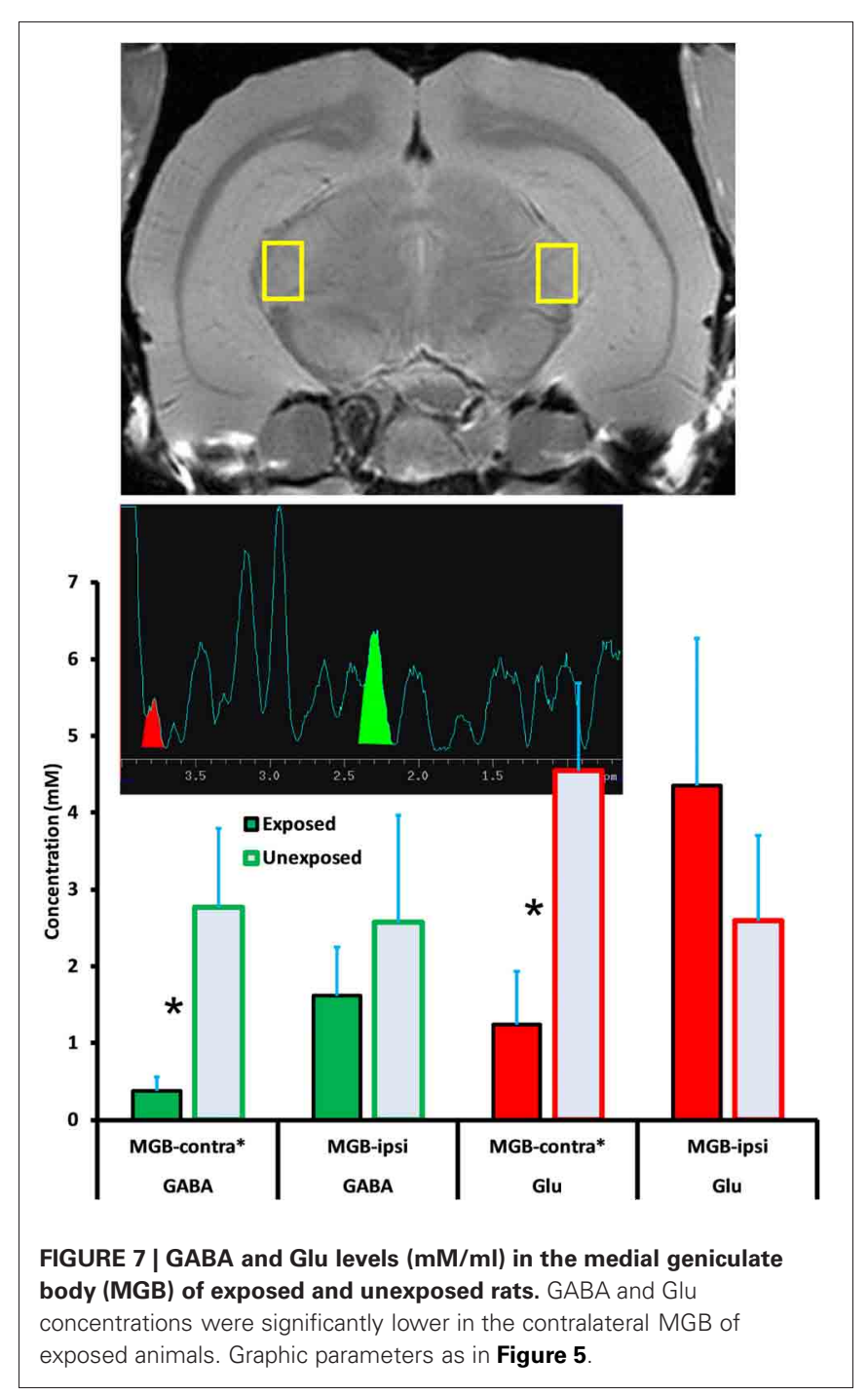

compound remains constant in concentration across conditions and VOI. The advantage of using an internal standard is that variation in local measurement conditions, for example shimming parameters, does not affect the reported values. The primary disadvantage of using an internal standard is that concentration of the standard compound might not be constant across individuals and conditions, thus affecting the reported ratios. A second disadvantage is that only relative level ratios can be reported, actual concentration levels remain unknown. When using an external standard, as in the present research, physical concentration levels are known and internal standard variation is irrelevant. However, when using an external standard, accuracy is dependent upon the calibration method. The external method described in the present study attempted to establish both realistic and stable calibration conditions (Figures 1 and 2). Calibration spectra were determined from phantoms similar in volume to the VOI and filled with realistic concentrations of GABA and Glu. Calibration spectra were also determined proximate in time to the brain spectra. Unfortunately attempts to simultaneously calibrate by including phantoms along with the brain at the time of data acquisition 


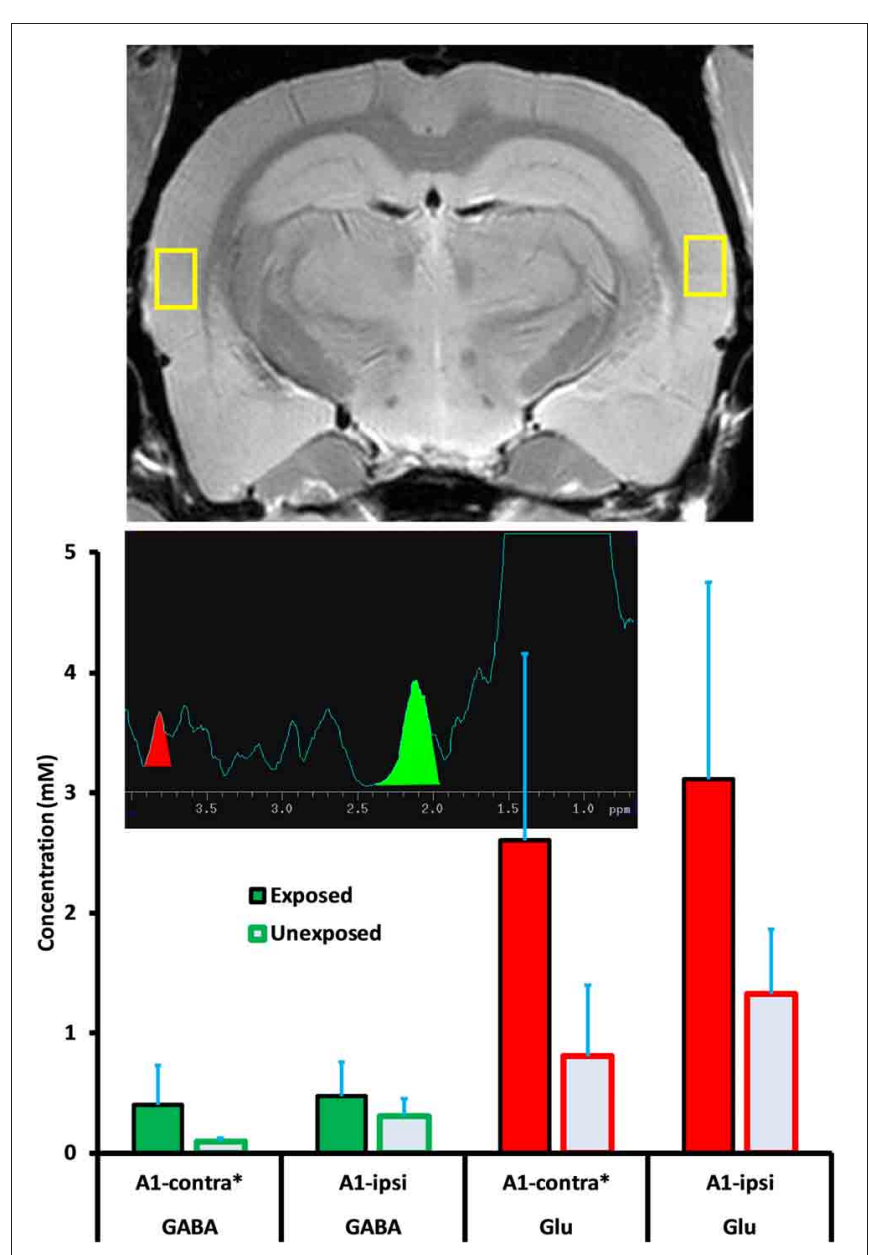

FIGURE 8 | GABA and Glu levels $(\mathrm{mM} / \mathrm{ml})$ in primary auditory cortex (A1) of exposed and unexposed rats. Although differences between exposed and unexposed animals were not statistically significant, significance levels may have been masked by measurement variability stemming from field anisotropy rather that neurochemical variability. Graphic parameters as in Figure $\mathbf{5}$

were not fruitful. Calibration phantoms included along with the brain produced field distortions that made shimming impossible. Also, placing phantoms alongside the brain put the phantoms in the field periphery where locally poor isotropy yielded calibration spectra of low quality.

Glu levels reported in the present study varied between 0.81 and $18.77 \mathrm{mM}$, while GABA levels varied between 0.09 and $2.77 \mathrm{mM}$, depending upon the VOI. These ex vivo levels are comparable to levels reported by others using similar ${ }^{1} \mathrm{H}-\mathrm{MRS}$ methods. Mlynarik et al. (Mlynarik et al., 2008) reported whole rat brain Glu levels of $10.3( \pm 8 \%)$ and GABA levels of $1.5( \pm 13 \%)$ $\mathrm{mM} / \mathrm{kg}$. In comparison to contemporary studies using traditional quantitative analytic methods, Glu levels reported in the present study were within range while GABA levels were somewhat higher. For example a recent report by (Zhu et al., 2011) using current-generation high performance liquid chromatography and whole brain homogenates, reported adult rat brain GABA levels of about $0.5( \pm 25 \%) \mathrm{mM} / \mathrm{mg}$ and Glu levels of
$10( \pm 10 \%) \mathrm{mM} / \mathrm{mg}$. The GABA discrepancy between the present study and that of (Zhu et al., 2011) may derive from differences between the methods, liquid chromatography depending upon solvent extraction from whole brain homogenates, and ${ }^{1} \mathrm{H}-\mathrm{MRS}$ depending on spectra derived from in situ tissue in the auditory pathway. It may also be that in the present study there was some GABA inflation, despite the use of 3-mercaptopropionic acid to arrest post-mortem elevation. A GABA inflation error, if present, should have affected exposed and unexposed rats equally since GABA (and Glu) levels were determined using the same procedural sequence for all animals (Table 2).

\section{GABA DECREASE IN THE MGB}

It has been hypothesized that a loss of inhibition in the central auditory pathway underpins chronic tinnitus (Holt et al., 2010; Wang et al., 2011; Brozoski et al., 2012). Indirect evidence supporting the hypothesis comes from pharmacological studies where systemically administered GABA agonists have been shown to decrease or eliminate behavioral evidence of tinnitus (Brozoski et al., 2007b, 2010; Yang et al., 2011). The hypothesis is also indirectly supported by studies showing increased levels of spontaneous neural activity in animals with evidence of tinnitus (Brozoski et al., 2002; Kaltenbach and Godfrey, 2008; Middleton et al., 2011). The role of the MGB, i.e., the auditory thalamus, in tinnitus is currently not well defined. Recent imaging evidence suggests that altered thalamic circuits may gate abnormal brainstem spontaneous activity to the cortex and limbic structures in tinnitus patients (Rauschecker et al., 2010). The MGB is an obligatory relay for ascending auditory information. Loss of inhibition in the MGB could increase the impact of spontaneous brainstem activity on higher processes, and induce the perception of sound in the absence of peripheral stimulation. Understanding the function of GABA in the MGB is currently evolving. The density of post-synaptic GABA-A receptors is quite low (Halonen et al., 2009). However, GABA-A receptors containing a $\delta$ subunit in substitution for the more common $\gamma$ subunit, have a high density in the MGB compared to other forebrain areas (Halonen et al., 2009; Richardson et al., 2011). $\delta$-subunit-containing GABA-A receptors appear to be primarily extra-synaptic and are responsible for mediating tonic inhibition (Richardson et al., 2011). This suggests that ambient extracellular GABA is important for regulating the general balance of inhibition/excitation in the MGB. Tinnitus may be mediated by loss of inhibitory volume transmission in the MGB mediated by down-regulation of extracellular GABA. Although the density of GABAergic interneurons in the rat MGB is apparently very low (Winer and Larue, 1996), glia have been shown to be a significant source of GABA in other brain areas (Olah et al., 2009). The loss of MGB GABA reported in the present experiment may reflect decreased extracellular-levels as well as lowered levels in glia. The net decrease in inhibition would increase rostral excitation.

Llinas et al. (2005) present a cortico-thalamic network model to account for tinnitus and other neuro-psychiatric disorders. In their model, cortical pyramidal cell feedback to the auditory thalamus, both indirectly, via the thalamic reticular nucleus, and directly, enables low-frequency thalmo-cortical oscillation. In this model, loss of afferent inhibitory input to the thalamus 


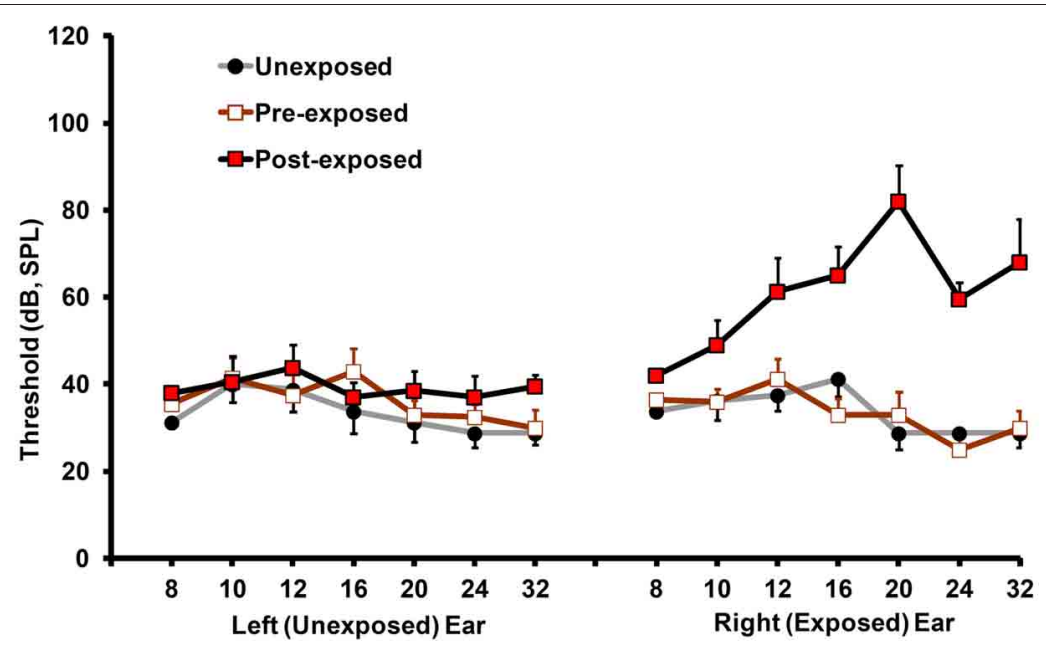

Test Stimulus Frequency $(\mathrm{kHz})$

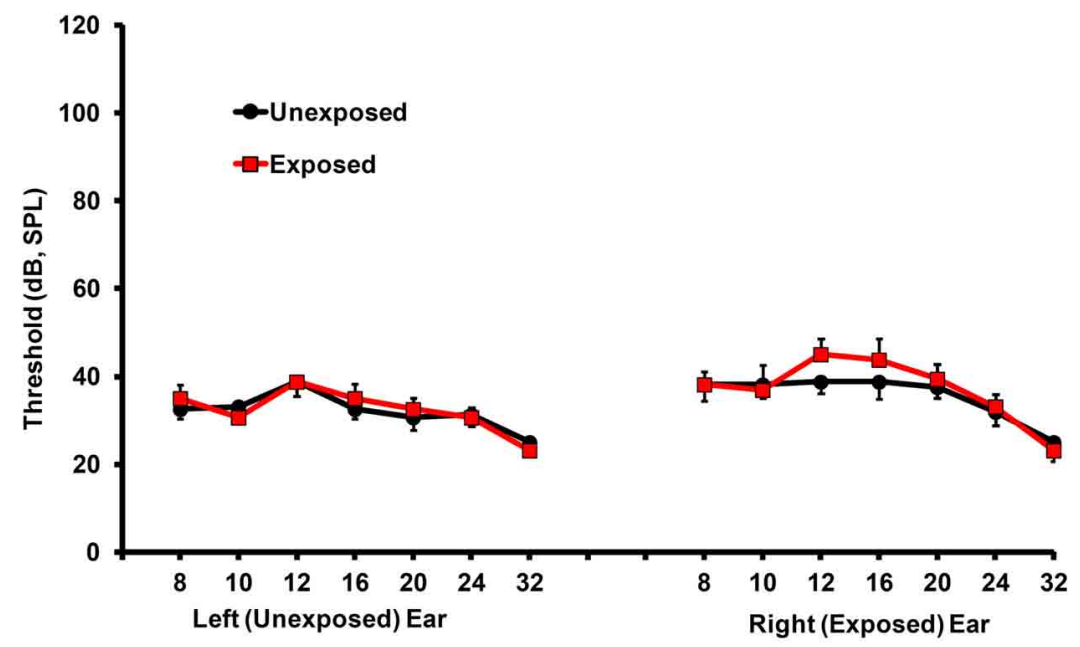

Test Stimulus Frequency $(\mathbf{k H z})$

FIGURE 9 | Auditory brainstem response thresholds for exposed and unexposed rats. Top panel: thresholds before and immediately after acoustic exposure. Significant threshold elevation was evident only in the exposed ear. Bottom panel: thresholds prior to spectroscopy show normal levels in both groups. Error bars show the standard error of the mean. is hypothesized to lead to "edge effect" enhancement of lowfrequency $(8 \mathrm{~Hz})$ oscillation, the result being the sensation of tinnitus. Interestingly the model also predicts increased lowfrequency oscillation, and presumably, associated tinnitus, in the presence of "protracted hyperpolarization of thalamic cells" (Llinas et al., 2005). Therefore, in the Llinas model, elevated GABA intrinsic to the MGB would be expected to produce chronic tinnitus. The present results, however, show just the opposite, with MGB GABA decreased in rats with tinnitus. Further research with cellular-level resolution will be required to answer more detailed questions concerning the role of GABA in specific circuits.

\section{Glu INCREASE IN DCN}

In addition to lowered MGB GABA levels, the present research also showed moderately elevated Glu levels in the DCN. Increased spontaneous neural activity in the DCN is associated with tinnitus in rodent models (Brozoski et al., 2002; Kaltenbach et al., 2004), while altered tonotopic organization of the auditory cortex has also been associated with tinnitus in rats (Yang et al., 2011). In fact there may be widespread increases in central gain functions following sensory loss, such as that produced by traumatic high-level sound exposure (Norena, 2011). Adaptive alterations in brain function are primarily mediated by plastic glutamatergic synapses via long-term potentiation (LTP) and long-term depression (LTD) (Zhuo, 2009; Lovinger, 2010; Kullmann and Lamsa, 2011). While LTP and LTD, as characterized in vitro, have durations of only an hour or so, it is clear that the same processes are involved in chronic changes that have been reported in adult rat Al in the context of specific pharmacological and acoustic exposures (Hogsden et al., 2011). Increased Glu levels in the DCN and A1 found in the present study, in rats with chronic tinnitus, may 
well reflect very long-term increases in excitatory neurotransmission. Both LTP and LTD have been identified in DCN local networks (Tzounopoulos et al., 2007). Furthermore, Glu associated alterations of cochlear nucleus function have been identified following cochlear damage (Zeng et al., 2009).

\section{NULL EFFECT IN THE INFERIOR COLLICULUS (IC)}

Given considerable evidence that the IC is involved in chronic tinnitus in animals (Brozoski et al., 2007a; Holt et al., 2010) and humans (Gu et al., 2010), it was somewhat surprising that neither GABA nor Glu levels in the IC were different in exposed versus unexposed animals (Figure 6). One explanation may be that average neural activity level was only slightly elevated in the IC of exposed animals. While significantly involved in tinnitus, the neural correlate in the IC may involve alterations in patterns of neural activity, such as infrequent bursts of high-frequency spikes and decreased inter-spike interval variance (Bauer et al., 2008), rather than gross level increases. As such, volume GABA and Glu alterations may not be evident. It also might be noted that studies reporting loss of IC GABA receptors after cochlear damage, also report permanent threshold elevations (Dong et al., 2010). In the present study hearing thresholds were essentially

\section{REFERENCES}

Bauer, C. A., and Brozoski, T. J. (2001). Assessing tinnitus and prospective tinnitus therapeutics using a psychophysical animal model. J. Assoc. Res. Otolaryngol. 2, 54-64.

Bauer, C. A., Turner, J. G., Caspary, D. M., Myers, K. S., and Brozoski, T. J. (2008). Tinnitus and inferior colliculus activity in chinchillas related to three distinct patterns of cochlear trauma. J. Neurosci. Res. 86, 2564-2578.

Brozoski, T. J., and Bauer, C. A. (2008). Learning about tinnitus from an animal model. Semin. Hear. 29, 242-258.

Brozoski, T. J., Bauer, C. A., and Caspary, D. M. (2002). Elevated fusiform cell activity in the dorsal cochlear nucleus of chinchillas with psychophysical evidence of tinnitus. J. Neurosci. 22, 2383-2390.

Brozoski, T. J., Caspary, D. M., Bauer, C. A., and Richardson, B. D. (2010). The effect of supplemental dietary taurine on tinnitus and auditory discrimination in an animal model. Hear. Res. 270, 71-80.

Brozoski, T. J., Ciobanu, L., and Bauer, C. A. (2007a). Central neural activity in rats with tinnitus evaluated with manganeseenhanced magnetic resonance imaging (MEMRI). Hear. Res. 228, 168-179.

Brozoski, T. J., Spires, T. J., and Bauer, C. A. (2007b). Vigabatrin, a GABA transaminase inhibitor, reversibly eliminates tinnitus in an animal model. J. Assoc. Res. Otolaryngol. 8, 105-118.

Brozoski, T. J., Wisner, K. W., Sybert, L. T., and Bauer, C. A. (2012). Bilateral dorsal cochlear nucleus lesions prevent acoustic-trauma induced tinnitus in an animal model. J. Assoc. Res. Otolaryngol. 13, 55-66.

Dong, S., Rodger, J., Mulders, W. H., and Robertson, D. (2010). Tonotopic changes in GABA receptor expression in guinea pig inferior colliculus after partial unilateral hearing loss. Brain Res. 1342, 24-32.

Gu, J. W., Halpin, C. F., Nam, E. C., Levine, R. A., and Melcher, J. R. (2010). Tinnitus, diminished sound-level tolerance, and elevated auditory activity in humans with clinically normal hearing sensitivity. J. Neurophysiol. 104, 3361-3370.

Guitton, M. J., and Dudai, Y. (2007). Blockade of cochlear NMDA receptors prevents long-term tinnitus during a brief consolidation window after acoustic trauma. Neural Plast. 2007, 80904.

Halonen, L. M., Sinkkonen, S. T., Chandra, D., Homanics, G. E., and Korpi, E. R. (2009). Brain regional distribution of GABA(A) receptors exhibiting atypical GABA agonism: roles of receptor subunits. Neurochem. Int. 55, 389-396.

Hogsden, J. L., Rosen, L. G., and Dringenberg, H. C. (2011). Pharmacological and deprivationinduced reinstatement of juvenile-like long-term potentiation in the primary auditory cortex normal at the time of tinnitus testing and spectroscopy (Figure 9, bottom panel).

\section{IMPLICATIONS FOR TINNITUS THERAPY}

There is no generally effective therapeutic intervention for tinnitus in current clinical application. In contrast, in animal models of tinnitus, several GABA agonists have been found to effectively attenuate or eliminate evidence of tinnitus (Brozoski et al., 2007b, 2010; Yang et al., 2011). Interestingly, while peripheral blockade of cochlear glutamatergic NMDA receptors has been shown to attenuate acoustic-trauma-induced tinnitus in a rat model (Guitton and Dudai, 2007), administration of the systemic NMDA antagonist ketamine, was not effective (Yang et al., 2011). Clinically, neither GABA agonists, for example the many available benzodiazepine derivatives, nor NMDA antagonists, have been shown to be effective in well-controlled trials. The present research suggests that a combined approach, targeting both decreased GABA function and elevated Glu function, may be more fruitful.

\section{ACKNOWLEDGMENTS}

Supported by the National Institute on Deafness and Other Communication Disorders, \#1R01DC009669-01. of adult rats. Neuroscience 186, 208-219.

Holt, A. G., Bissig, D., Mirza, N., Rajah, G., and Berkowitz, B. (2010). Evidence of key tinnitus-related brain regions documented by a unique combination of manganeseenhanced MRI and acoustic startle reflex testing. PLoS One 5, e14260. doi: 10.1371/journal.pone.0014260

Kaltenbach, J. A., and Godfrey, D. A. (2008). Dorsal cochlear nucleus hyperactivity and tinnitus: are they related? Am. J. Audiol. 17, S148-S161.

Kaltenbach, J. A., Zacharek, M. A., Zhang, J., and Frederick, S. (2004). Activity in the dorsal cochlear nucleus of hamsters previously tested for tinnitus following intense tone exposure. Neurosci. Lett. 355 121-125.

Kullmann, D. M., and Lamsa, K. P. (2011). LTP and LTD in cortical GABAergic interneurons: emerging rules and roles. Neuropharmacology 60, 712-719.

Llinas, R., Urbano, F. J., Leznik, E., Ramirez, R. R., and van Marle, H. J. (2005). Rhythmic and dysrhythmic thalamocortical dynamics: GABA systems and the edge effect. Trends Neurosci. 28, 325-333.

Lovinger, D. M. (2010). Neurotransmitter roles in synaptic modulation, plasticity and learning in the dorsal striatum. Neuropharmacology 58, 951-961.

Middleton, J. W., Kiritani, T., Pedersen, C., Turner, J. G., Shepherd, G. M., and Tzounopoulos, T. (2011). Mice with behavioral evidence of tinnitus exhibit dorsal cochlear nucleus hyperactivity because of decreased GABAergic inhibition. Proc. Natl. Acad. Sci. U.S.A. 108, 7601-7606.

Mlynarik, V., Cudalbu, C., Xin, L., and Gruetter, R. (2008). 1H NMR spectroscopy of rat brain in vivo at 14.1Tesla: improvements in quantification of the neurochemical profile. J. Magn. Reson. 194, 163-168.

Muhr, P., and Rosenhall, U. (2011). The influence of military service on auditory health and the efficacy of a Hearing Conservation Program. Noise Health 13, 320-327.

Nondahl, D. M., Cruickshanks, K. J., Wiley, T. L., Klein, R., Klein, B. E., and Tweed, T. S. (2002). Prevalence and 5-year incidence of tinnitus among older adults: the epidemiology of hearing loss study. J. Am. Acad. Audiol. 13, 323-331.

Norena, A. J. (2011). An integrative model of tinnitus based on a central gain controlling neural sensitivity. Neurosci. Biobehav. Rev. 35, 1089-1109.

Odintsov, B. (2011). Tunable RadioFrequency Coil. USA patent application 61081954. November 1, 2011.

Olah, S., Fule, M., Komlosi, G., Varga, C., Baldi, R., Barzo, P., and Tamas, G. (2009). Regulation of cortical microcircuits by unitary GABAmediated volume transmission. Nature 461, 1278-1281.

Puts, N. A., Edden, R. A., Evans, C. J., Mcglone, F., and Mcgonigle, D. 
J. (2011). Regionally specific human GABA concentration correlates with tactile discrimination thresholds. J. Neurosci. 31, 16556-16560.

Rauschecker, J. P., Leaver, A. M., and Muhlau, M. (2010). Tuning out the noise: limbic-auditory interactions in tinnitus. Neuron 66, 819-826.

Richardson, B. D., Ling, L. L., Uteshev, V. V., and Caspary, D. M. (2011). Extrasynaptic GABA(A) receptors and tonic inhibition in rat auditory thalamus. PLoS One 6, e16508. doi: 10.1371/journal.pone.0016508

Roberts, L. E., Eggermont, J. J., Caspary, D. M., Shore, S. E., Melcher, J. R., and Kaltenbach, J. A. (2010). Ringing ears: the neuroscience of tinnitus. J. Neurosci. 30, 14972-14979.

Stagg, C. J., Bachtiar, V., and JohansenBerg, H. (2011a). The role of GABA in human motor learning. Curr. Biol. 21, 480-484.

Stagg, C. J., Bachtiar, V., and JohansenBerg, H. (2011b). What are we measuring with GABA magnetic resonance spectroscopy? Commun Integr. Biol. 4, 573-575.

Tzounopoulos, T., Rubio, M. E., Keen, J. E., and Trussell, L. O. (2007). Coactivation of pre- and postsynaptic signaling mechanisms determines cell-specific spike-timing-dependent plasticity. Neuron 54, 291-301.

van der Heyden, J. A., and Korf, J. (1978). Regional levels of GABA in the brain: rapid semiautomated assay and prevention of postmortem increase by 3-mercapto-propionic acid. J. Neurochem. 31, 197-203.

Wang, H., Brozoski, T. J., and Caspary, D. M. (2011). Inhibitory neurotransmission in animal models of tinnitus: maladaptive plasticity. Hear. Res. 279, 111-117.

Winer, J. A., and Larue, D. T. (1996). Evolution of GABAergic circuitry in the mammalian medial geniculate body. Proc. Natl. Acad. Sci. U.S.A. 93, 3083-3087.
Yang, S., Weiner, B. D., Zhang, L. S., Cho, S. J., and Bao, S. (2011) Homeostatic plasticity drives tinnitus perception in an animal model. Proc. Natl. Acad. Sci. U.S.A. 108, 14974-14979.

Zeng, C., Nannapaneni, N., Zhou, J., Hughes, L. F., and Shore, S. (2009). Cochlear damage changes the distribution of vesicular glutamate transporters associated with auditory and nonauditory inputs to the cochlear nucleus. J. Neurosci. 29 , 4210-4217.

Zhu, K. Y., Fu, Q., Leung, K. W., Wong, Z. C., Choi, R. C., and Tsim, K. W. (2011). The establishment of a sensitive method in determining different neurotransmitters simultaneously in rat brains by using liquid chromatography-electrospray tandem mass spectrometry. $J$. Chromatogr. B Analyt. Technol. Biomed. Life Sci. 879, 737-742.

Zhuo, M. (2009). Plasticity of NMDA receptor NR2B subunit in memory and chronic pain. Mol. Brain 2, 4.
Conflict of Interest Statement: The authors declare that the research was conducted in the absence of any commercial or financial relationships that could be construed as a potential conflict of interest.

Received: 21 December 2011; accepted: 08 February 2012; published online: 24 February 2012.

Citation: Brozoski T, Odintsov $B$ and Bauer C (2012) Gamma-aminobutyric acid and glutamic acid levels in the auditory pathway of rats with chronic tinnitus: a direct determination using high resolution point-resolved proton magnetic resonance spectroscopy ( $\left.{ }^{1} \mathrm{H}-\mathrm{MRS}\right)$. Front. Syst. Neurosci. 6:9. doi: 10.3389/ fnsys.2012.00009

Copyright (c) 2012 Brozoski, Odintsov and Bauer. This is an open-access article distributed under the terms of the Creative Commons Attribution Non Commercial License, which permits noncommercial use, distribution, and reproduction in other forums, provided the original authors and source are credited. 